\title{
Effects of Substrate Temperature on Structural Properties of Tin Oxide Films Produced by Plasma Oxidation after Thermal Evaporation
}

\author{
M. AlaF*, M.O. Guler, D. Gultekin and H. Akbulut \\ Sakarya University, Dept. of Metallurgical \& Materials Engineering, 54187, Sakarya, Turkey
}

\begin{abstract}
In this study, tin film was thermally evaporated onto a stainless steel substrate in an argon atmosphere. The tin films were then subjected to a DC plasma oxidation process using an oxygen/argon gas mixture. Three different substrate temperatures $\left(100{ }^{\circ} \mathrm{C}, 150{ }^{\circ} \mathrm{C}\right.$, and $\left.200{ }^{\circ} \mathrm{C}\right)$ and three different oxygen partial pressures $(12.5 \%, 25 \%$, and $50 \%)$ were used to investigate the physical and microstructural properties of the films. The surface properties were studied by scanning electron microscopy, X-ray diffraction, atomic force microscopy and a four-point probe electrical resistivity measurement. The grain size and texture coefficient of the tin oxide films were calculated. Both $\mathrm{SnO}$ and $\mathrm{SnO}_{2}$ films with grain sizes of 13-43 nm were produced, depending on the oxygen partial pressure. $\mathrm{SnO}$ films have flower- and flake-like nanostructures, and $\mathrm{SnO}_{2}$ films have grape-like structures with nanograins. The resistivity values for the $\mathrm{SnO}_{2}$ phase were found to be as low as $10^{-5} \Omega \mathrm{cm}$ and were observed to decrease with increasing substrate temperature.
\end{abstract}

DOI: 10.12693/APhysPolA.123.326

PACS: 64.70.fm, 73.61.At, 81.16.Pr

\section{Introduction}

There are two main oxides of tin: stannic oxide $\left(\mathrm{SnO}_{2}\right)$ and stannous oxide $(\mathrm{SnO})$. The existence of these two oxides reflects the dual valency of tin, which has oxidation states of $2+$ and $4+$. The applications of tin oxides include their use as catalysts, gas sensors, heat reflection filters, transparent conducting coatings, and anode materials [1]. One of the semiconducting oxide materials, $\mathrm{SnO}$, has received increased attention because it is known to be a $p$-type semiconductor with a wide band gap $\left(E_{\mathrm{g}}=2.5 \div 3.0 \mathrm{eV}\right)$, whereas most oxide semiconductors have $n$-type features.

Recently, $\mathrm{SnO}$ has been studied as an anode material for Li-ion batteries because the capacity of $\mathrm{SnO}$ surpasses that of graphite or $\mathrm{SnO}_{2}$. Because $\mathrm{SnO}$ is unstable at temperatures over $270^{\circ} \mathrm{C}$, in contrast with $\mathrm{SnO}_{2}$, the former is simply reported as a precursor or an intermediate phase in the process of fabricating the $\mathrm{SnO}_{2}$ nanostructures [2].

In this study, pure metallic tin was evaporated onto stainless steel substrates in an argon atmosphere at a pressure of 1.0 Pa, and the deposited films have been oxidized with dc (direct current) plasma in an $\mathrm{Ar} / \mathrm{O}_{2}$ gas mixture. The effect of substrate temperature and oxygen partial pressure on the morphology, structure, and physical properties of the films was investigated. The goal of this work is to develop an authentic method with which to produce and characterize nanosized tin oxide films that is low-cost and that provides an easy way to control the film properties.

\footnotetext{
* corresponding author
}

\section{Experiment details}

$\mathrm{SnO}$ and $\mathrm{SnO}_{2}$ films were manufactured in two steps: thermal evaporation and dc plasma oxidation in a multifunctional magnetron sputtering physical vapor deposition (PVD) unit. The thin films were deposited onto cleaned and polished 316L stainless steel substrates. First, high purity metallic tin $(99.999 \%)$ was placed in a Mo boat in the deposition chamber, which was evacuated to $10^{-4} \mathrm{~Pa}$ by a turbomolecular pump and then backfilled with argon to a pressure of $1 \mathrm{~Pa}$. In the second step, $\mathrm{SnO}$ and $\mathrm{SnO}_{2}$ thin films have been produced by dc plasma oxidation from the thermally evaporated tin films. The plasma oxidation of the tin films was conducted using a high-purity oxygen (99.999\%) and argon $(99.9999 \%)$ gas mixture. Three different substrate temperatures of $100^{\circ} \mathrm{C}, 150{ }^{\circ} \mathrm{C}$, and $200^{\circ} \mathrm{C}$ and three different oxygen partial pressures of $12.5 \%, 25 \%$, and $50 \%$ (the rest of the mixture is argon), all with a dc power of $80 \mathrm{~W}$, were chosen for plasma oxidation. The oxidation time and total chamber pressure for each oxidation were kept constant at $1 \mathrm{~h}$ and $1.6 \mathrm{~Pa}$.

An X-ray diffractometer (Rigaku D/MAX 2000), scanning electron microscopy (JEOL 6060LV) and atomic force microscopy (Quesant) and a four-point probe resistivity measurement (Bellsonics PRO4) using a WC probe has been used to characterization of the films. The grain sizes of the thin films were calculated using Scherrer's formula. Texture coefficients (TC) can be determined according to the formula [3]:

$$
\mathrm{TC}(h k l)=\frac{I(h k l) / I_{0}(h k l)}{\sum_{N} I(h k l) / I_{0}(h k l)},
$$

where $I_{0}(h k l)$ and $I(h k l)$ are the standard X-ray intensity of the $\mathrm{SnO}_{2}$ powder and the measured X-ray intensity, and $N$ is the reflection number. 


\section{Results and discussion}

\subsection{Thermal evaporation of $S n$ coatings}

Figure 1 shows a scanning electron microscopy (SEM) image and a typical X-ray diffraction (XRD) pattern for the pure tin $(\mathrm{Sn})$ films evaporated onto the stainless steel substrates in an argon atmosphere at a pressure of $1.0 \mathrm{~Pa}$ (JCPDS file no. 01-086-2264 for powder Sn). No obvious reflection peaks from impurities were detected, providing evidence of the high purity of the product. The (220), (211) and (200) peaks are the strongest peaks observed for the film evaporated onto a stainless steel substrate in a $1.0 \mathrm{~Pa}$ argon atmosphere.
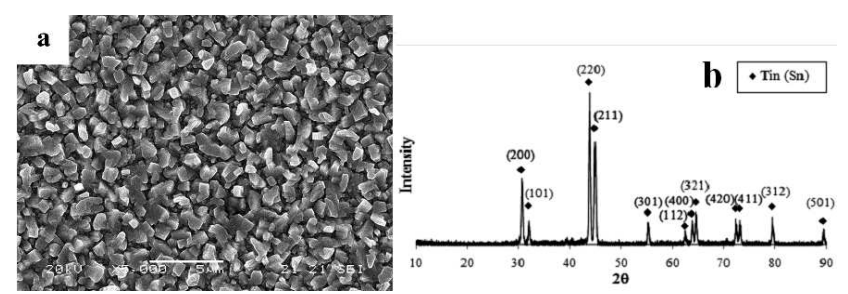

Fig. 1. (a) SEM images, (b) XRD pattern of pure tin (Sn) film evaporated at $1 \mathrm{~Pa}$ Ar.

In our previous study [4], we deposited tin using three different argon pressures of $0.5 \mathrm{~Pa}, 1.0 \mathrm{~Pa}$, and 1.5 Pa. For the lowest chamber pressure, the strongest peak was the (200) orientation. When the pressure was increased, the preferred orientation changed from (200) to (220). Texture coefficients are $0.27,0.1,1.67$, and 0.72 for the (200), (101), (220), and (211) planes, respectively. After thermal evaporation onto a stainless steel substrate, tin exhibits a crystalline microstructure with epitaxial grains. The calculated grain size with Scherrer's formula of the tin film that was thermally evaporated in a $1.0 \mathrm{~Pa}$ Ar atmosphere is $34 \mathrm{~nm}$.

\subsection{DC plasma oxidation}

After the thermal evaporation process, the tin samples were subjected to a plasma oxidation process at three different oxygen partial pressures of $12.5 \%, 25 \%$, and
$50 \%$ and three different substrate temperatures of $100^{\circ} \mathrm{C}$, $150{ }^{\circ} \mathrm{C}$, and $200^{\circ} \mathrm{C}$ to produce tin oxide films. Figure 2 presents the XRD patterns of the $\mathrm{SnO}$ and $\mathrm{SnO}_{2}$ films. The XRD patterns of the tin oxide films produced in a $12.5 \% \mathrm{O}_{2}$ plus $87.5 \% \mathrm{Ar}$ atmosphere at three different substrate temperatures are presented in Fig. 2a. The films have an $\mathrm{SnO}$ structure, which agrees well with the standard data files (JPDS 01-072-1012), and all of the films have a crystalline structure. The XRD patterns show that the $\mathrm{SnO}$ nanostructures had preferred orientations of (110) and (101). The same preferred orientation of SnO films was also observed by Shin et al. [2]. They produced nanostructured tetragonal $\mathrm{SnO}$ films with preferred orientations of (110) and (101) using the vapor transport process. Increasing the substrate temperature resulted in an increase in the intensity of the XRD peaks corresponding to the (110), (101) and (211) planes.

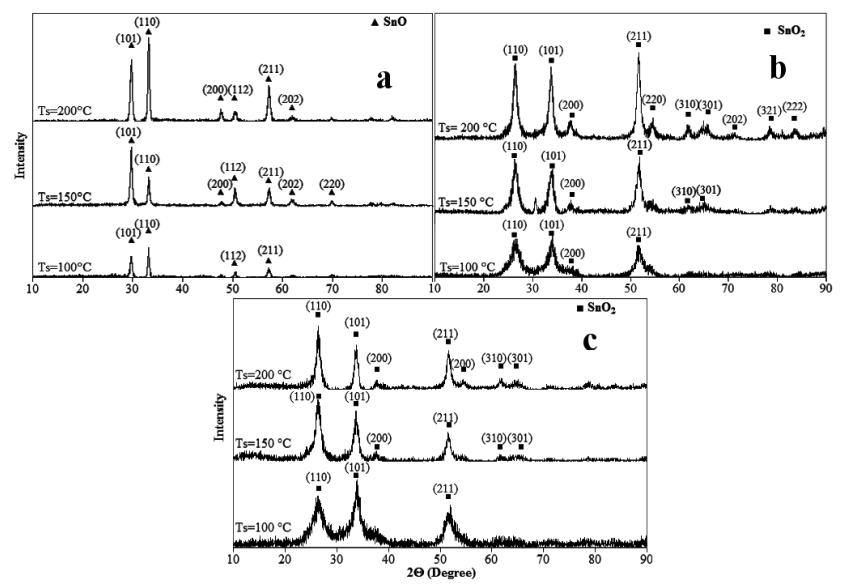

Fig. 2. XRD patterns of $\mathrm{SnO}$ and $\mathrm{SnO}_{2}$ films produced at $12.5 \% \mathrm{O}_{2}$ (a), $25 \% \mathrm{O}_{2}$ (b) and $50 \% \mathrm{O}_{2}$ (c) partial pressure at three different substrate temperatures.

Table presents the textural parameters of the $\mathrm{SnO}$ and $\mathrm{SnO}_{2}$ films as a function of substrate temperature. The grain sizes of the $\mathrm{SnO}$ films that were plasma oxidized at $12.5 \% \mathrm{O}_{2}$ partial pressure were recorded as $43.06 \mathrm{~nm}$, $36.01 \mathrm{~nm}$, and $29.0 \mathrm{~nm}$ for substrate temperatures of $100^{\circ} \mathrm{C}, 150^{\circ} \mathrm{C}$, and $200^{\circ} \mathrm{C}$, respectively.

Texture coefficients (TC) of $\mathrm{SnO}$ and $\mathrm{SnO}_{2}$ films produced.

TABLE

\begin{tabular}{|c|c|c|c|c|c|c|c|c|c|c|c|c|c|c|}
\hline \multirow{3}{*}{$\begin{array}{c}\text { Substrate } \\
\text { temperature }\end{array}$} & \multicolumn{5}{|c|}{$12.5 \%$ oxygen $(\mathrm{SnO})$} & \multicolumn{5}{|c|}{$25 \%$ oxygen $\left(\mathrm{SnO}_{2}\right)$} & \multicolumn{4}{|c|}{$50 \%$ oxygen $\left(\mathrm{SnO}_{2}\right)$} \\
\hline & \multicolumn{5}{|c|}{ Planes } & \multicolumn{5}{|c|}{ Planes } & \multicolumn{4}{|c|}{ Planes } \\
\hline & $(101)$ & $(110)$ & $(200)$ & $(112)$ & $(211)$ & $(110)$ & $(101)$ & $(200)$ & $(211)$ & $(220)$ & $(110)$ & $(101)$ & $(200)$ & $(211)$ \\
\hline $100^{\circ} \mathrm{C}$ & 0.34 & 1.81 & 0.31 & 0.35 & 0.64 & 0.43 & 0.93 & 0.66 & 0.91 & 1.03 & 0.42 & 0.90 & 0.22 & 0.59 \\
\hline $150^{\circ} \mathrm{C}$ & 0.78 & 1.50 & 0.34 & 1.70 & 1.04 & 0.64 & 0.84 & 0.52 & 1.25 & 1.50 & 2.55 & 2.05 & 0.15 & 0.72 \\
\hline $200^{\circ} \mathrm{C}$ & 0.42 & 2.18 & 0.55 & 0.21 & 1.01 & 0.72 & 0.82 & 0.30 & 1.66 & 1.74 & 1.07 & 1.0 & 0.72 & 1.18 \\
\hline
\end{tabular}

The SEM images of the SnO films oxidized at $12.5 \% \mathrm{O}_{2}$ partial pressure are shown in Fig. 3 for three different substrate temperatures of $100^{\circ} \mathrm{C}, 150^{\circ} \mathrm{C}$, and $200^{\circ} \mathrm{C}$. The $\mathrm{SnO}$ phase exhibited equiaxed nanograins at a sub- 
strate temperature of $100^{\circ} \mathrm{C}$. Interestingly, the $\mathrm{SnO}$ structures appeared to have flower geometry when the substrate temperature increased to 150 and $200^{\circ} \mathrm{C}$, so these structures were called nanoflowers. In the literature it was reported that the $\mathrm{SnO}$ nanocrystals can exhibit different geometries, such as a branched nanostructure [2] nanoribbons [5], platelets [6], sheets [7], rossets [8], and whiskers [9], that are formed according to the production method and the deposition conditions.

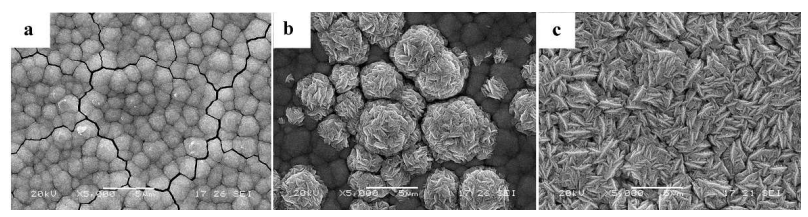

Fig. 3. SEM images of $\mathrm{SnO}$ films produced at $12.5 \% \mathrm{O}_{2}$ partial pressure at three different substrate temperatures (a) $100{ }^{\circ} \mathrm{C}$, (b) $150{ }^{\circ} \mathrm{C}$, (c) $200{ }^{\circ} \mathrm{C}$.

AFM studies were conducted on the $\mathrm{SnO}$ films that were oxidized at three different substrate temperatures and they are shown in Fig. 4. AFM images were recorded from two $10 \times 10 \mu \mathrm{m}^{2}$ areas within the films: one in the central portion of the substrate and the other at a lateral center position.

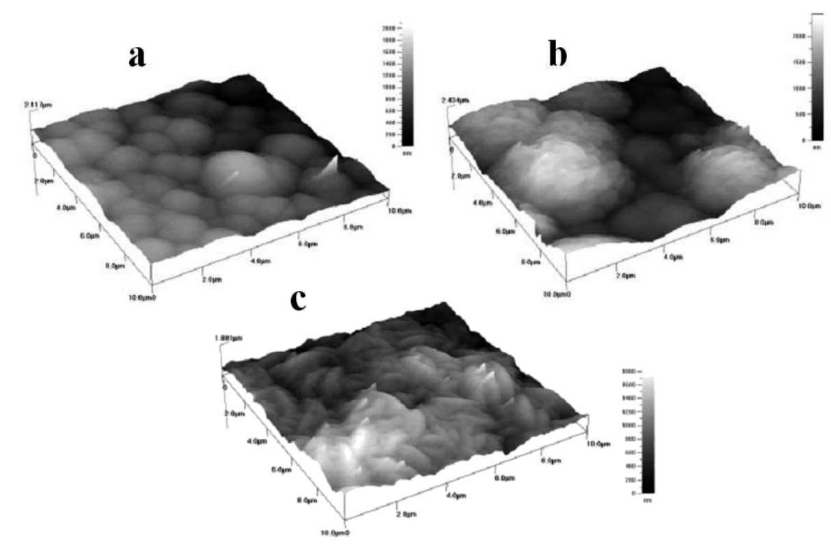

Fig. 4. AFM images of $\mathrm{SnO}$ films produced at $12.5 \% \mathrm{O}_{2}$ partial pressure at three different substrate temperatures (a) $100{ }^{\circ} \mathrm{C}$, (b) $150{ }^{\circ} \mathrm{C}$, (c) $200{ }^{\circ} \mathrm{C}$.

The crystal structure of the plasma oxidized pure $\mathrm{Sn}$ depositions under the $25 \%$ and $50 \% \mathrm{O}_{2}$ partial pressure $\mathrm{SnO}_{2}$ films was determined using the X-ray diffraction technique. All the films produced at $25 \%$ and $50 \% \mathrm{O}_{2}$ partial pressure exhibited an $\mathrm{SnO}_{2}$ polycrystalline structure, as shown in Fig. $2 \mathrm{~b}$ and Fig. 2c, which agrees well with the standard data files (JPDS 01-077-0447). A comparison of the $\mathrm{SnO}_{2}$ films with the same oxygen partial pressures at different substrate temperatures shows that some crystallographic characteristics changed with temperature. As the substrate temperature increases, the crystallinity of the films improves, which is confirmed by the intensity and sharpness of the XRD peaks of the $\mathrm{SnO}_{2}$ phase. Similar results were also reported by some researchers [9-11].

The SEM images of the $\mathrm{SnO}_{2}$ thin films deposited by thermal evaporation from metallic tin at $1.0 \mathrm{~Pa} \mathrm{Ar}$ pressure and then subsequently plasma oxidized at three different substrate temperatures and at $50 \% \mathrm{O}_{2}$ partial pressures are presented in Fig. 5. $\mathrm{SnO}_{2}$ films plasma oxidized at $50 \% \quad \mathrm{O}_{2}$ partial pressure are similar to the morphology presented in Fig. 5 .

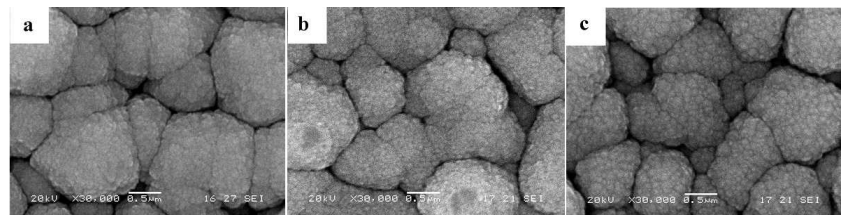

Fig. 5. SEM images of $\mathrm{SnO}_{2}$ films produced at $25 \% \mathrm{O}_{2}$ partial pressure at three different substrate temperatures (a) $100{ }^{\circ} \mathrm{C}$, (b) $150{ }^{\circ} \mathrm{C}$, (c) $200{ }^{\circ} \mathrm{C}$.

The grain sizes of the $\mathrm{SnO}_{2}$ films that were plasma oxidized at $25 \% \mathrm{O}_{2}$ partial pressure were calculated to be $13.04 \mathrm{~nm}, 18.04 \mathrm{~nm}$, and $21.6 \mathrm{~nm}$ for substrate temperatures of $100^{\circ} \mathrm{C}, 150{ }^{\circ} \mathrm{C}$, and $200^{\circ} \mathrm{C}$, respectively. A similar trend in the increase of grain size was also obtained for the $\mathrm{SnO}_{2}$ films produced at $50 \% \mathrm{O}_{2}$ partial pressure $(13 \mathrm{~nm}, 17.37 \mathrm{~nm}$, and $23.7 \mathrm{~nm})$. In conclusion, the grain sizes of the $\mathrm{SnO}_{2}$ films that were plasma oxidized at $25 \%$ and $50 \% \mathrm{O}_{2}$ partial pressure increased as the substrate temperature increased.

\subsection{Resistivity}

The electrical resistivity of the thin films was measured by a four-point probe resistivity measurement using a $\mathrm{WC}$ probe. Because the $\mathrm{SnO}$ phase exhibited high resistivity, the test apparatus has failed to measure the resistivity values for the samples that were plasma oxidized at $12.5 \%$ and $25 \% \mathrm{O}_{2}$ partial pressure at substrate temperatures of $100^{\circ} \mathrm{C}$ and $150^{\circ} \mathrm{C}$. The resistivity values that were measured for the samples that were plasma oxidized at $12.5 \%$ and $25 \% \mathrm{O}_{2}$ partial pressure were recorded as $3.1 \times 10^{-4} \Omega \mathrm{cm}$ and $6.0 \times 10^{-4} \Omega \mathrm{cm}$. The resistivity values of $\mathrm{SnO}_{2}$ films that were plasma oxidized at $50 \% \mathrm{O}_{2}$ partial pressure are $7.2 \times 10^{-4} \Omega \mathrm{cm}, 4.8 \times 10^{-4} \Omega \mathrm{cm}$ and $1.08 \times 10^{-5} \Omega \mathrm{cm}$ for substrate temperatures of $100^{\circ} \mathrm{C}$, $150{ }^{\circ} \mathrm{C}$, and $200^{\circ} \mathrm{C}$, respectively. Increasing the substrate temperature could lead to increased grain sizes and improved crystallinity of the $\mathrm{SnO}_{2}$ films.

Consequently, a higher substrate temperature could lead to the formation of lower resistance or higher conductivity films because of the increase in mobility and/or carrier density at higher substrate temperatures [12].

\section{Conclusions}

Nanocrystalline tin films with a grain size of $34 \mathrm{~nm}$ were deposited onto stainless steel substrates in a $1.0 \mathrm{~Pa}$ 
argon atmosphere from a metallic pure tin target using the thermal evaporation technique. Different tin oxide structures and morphologies were produced by changing the partial pressure of $\mathrm{O}_{2}$ and the substrate temperature during plasma oxidation. Increasing the substrate temperature resulted in more crystalline structures for both the $\mathrm{SnO}$ and $\mathrm{SnO}_{2}$ films. Plasma oxidized pure $\mathrm{Sn}$ coatings at $12.5 \% \mathrm{O}_{2}$ partial pressure exhibited a tetragonal $\mathrm{SnO}$ structure. Plasma oxidized pure Sn coatings for $12.5 \% \mathrm{O}_{2}$ exhibited equiaxed nanograins (43.06 $\mathrm{nm}$ ) at $100{ }^{\circ} \mathrm{C}$, but the morphology changed to a flower-like geometry when the substrate temperature increased to $150^{\circ} \mathrm{C}(36.01 \mathrm{~nm})$ and $200{ }^{\circ} \mathrm{C}(29.0 \mathrm{~nm})$. Increasing the $\mathrm{O}_{2}$ partial pressure to $25 \%$ and $50 \%$ resulted in a conversion to the cassiterite $\mathrm{SnO}_{2}$ phase with grain sizes between 13.0 and $17.37 \mathrm{~nm}$ and without the $\mathrm{SnO}$ structure. Increasing substrate temperature resulted in increasing grain size. The electrical resistivity of the $\mathrm{SnO}_{2}$ films is in the range of $7.2 \times 10^{-4}-1.08 \times 10^{-5} \Omega \mathrm{cm}$. The resistivity values decreased with increasing substrate temperature.

\section{Acknowledgments}

The authors would like to acknowledge the financial support of Scientific and Technical Research council of Turkey (TUBITAK) under the contract no. 109M464.

\section{References}

[1] Q. Liu, Z. Liu, L. Feng, Comput. Mater. Sci. 47, 1016 (2010)
[2] J.H. Shin, J.Y. Song, Y.H. Kim, H.M. Park, Mater. Lett. 64, 1120 (2010)

[3] R.Y. Korotkov, P. Ricou, A.J.E. Farran, Thin Solid Films 502, 79 (2006)

[4] M. Alaf, M.O. Guler, D. Gultekin, M. Uysal, A. Alp, H. Akbulut, Vacuum 83, 292 (2009).

[5] H. Uchiyama, H. Imai, Cryst. Growth Des. 7, 841 (2007)

[6] S. Wang, S. Xie, H. Li, S. Yan, K. Fan, M. Qiao, Chem. Commun., 507 (2005)

[7] Y. Pei, S. Wang, Q. Zhou, S.-H. Xie, M.-H. Qiao, Z.-Y. Jiang, K.-N. Fan, Chin. J. Chem. 25, 1385 (2007)

[8] H. Uchiyama, H. Imai, Langmuir 24, 9038 (2008)

[9] Z. Jia, L. Zhu, G. Liao, Y. Yu, Y. Tang, Solid State Commun. 132, 79 (2004).

[10] A. Yadav, E.U. Masumdar, A.V. Moholkar, M. Neumann-Spallart, K.Y. Rajpure, C.H. Bhosale, J. Alloys Comp. 488, 350 (2009)

[11] S.J. Ikhmayies, R.N.A. Bitar, Mater. Sci. Semicond. Proc. 12, 122 (2009).

[12] V. Senthilkumar, P. Vickraman, Curr. Appl. Phys. 10, $880(2010)$ 